\title{
Freqüència de pràctica física i autoconcepte físic multidimensional en l'adolescència
}

\author{
Frequency of Physical Exercise and Physical Multidimensional Self-Awareness \\ in Adolescence
}

RAFAEL E. REIGAL GARRIDO

Departament d'Educació Física

Fundación Diocesana de Enseñanza Santa María de la Victoria (Málaga)

ANTONIO VIDERA GARCÍA

Departament de Psicologia Social, Antropologia Social, Treball Social i Serveis Socials Universidad de Málaga

\author{
Autor per a la correspondència \\ Rafael E. Reigal Garrido \\ reigal_garrido@hotmail.com
}

Resum

El present treball explora les relacions existents entre la pràctica físicoesportiva i l'autoconcepte físic multidimensional, posades de manifest en diverses investigacions (Alvariñas \& González, 2004; Candel, Olmedilla, \& Blas, 2008; Hellín, 2007; Goñi \& Zulaica, 2000). La mostra utilitzada va estar composta per 2.079 adolescents de Màlaga capital, estudiants de 3r i 4t de secundària i 1r de batxillerat, en edats compreses entre els 14 i 17 anys $(M=15,62 ; D T=0,95)$. Després de recollir dades relatives a la pràctica física, vam obtenir informació sobre el seu autoconcepte físic mitjançant el Qüestionari d'Autoconcepte Físic (CAF) elaborat per Goñi, Ruiz de Azúa i Liberal (2004), en el qual es poden establir les dimensions següents: habilitat física, condició física, atractiu físic i força, a més de mesurar l'autoconcepte físic general i l'autoconcepte general. Els resultats trobats indiquen que els individus que tenien una major freqüència d'activitat físic esportiva setmanal posseïen majors puntuacions en el Qüestionari d'Autoconcepte Físic (CAF), amb diferències significatives en tots els casos menys en la subescala autoconcepte general.

Paraules clau: autoconcepte físic, pràctica física, adolescència

\begin{abstract}
Frequency of Physical Exercise and Physical Multidimensional Self-Awareness in Adolescence

This work explores the relationships existing between the practice of physical sports and physical multidimensional selfawareness, brought out in various research (Alvariñas \& González, 2004; Candel, Olmedilla, \& Blas, 2008; Hellín, 2007; Goñi \& Zulaica, 2000). The sample used was composed of 2,079 adolescents from Malaga city, students in the $3 \mathrm{rd}$ and 4 th year of secondary school and the 1st year baccalaureate, of ages between 14 and 17 years $(M=15.62 ; D T=0.95)$. After collecting data relating to physical practice, we obtained information on their physical self-awareness from the Physical Selfawareness Questionnaire (PSQ) prepared by Goñi, Ruiz de Azúa, and Liberal, I. (2004), in which the following dimensions can be established: physical ability, physical condition, physical attraction and strength, as well as measuring general physical self-awareness and general self-awareness. The results found indicated that individuals who practised more physical sports per week gained better points in the Physical Self-awareness Questionnaire (PSQ), with significant differences in all cases except in the general self-awareness sub-scale.
\end{abstract}

Keywords: physical self-awareness, physical practice, adolescence

\section{Introducció}

L'autoconcepte és un constructe considerat com un indicador de benestar psicològic (Pastor, 1999) i es pot definir com el conjunt de percepcions que una persona té de si mateixa (Esnaola, 2005). Per Aguilar (2003), té la seva base en tres aspectes fonamentals: biològic, cognitiu i experiencial. A mitjan anys setanta del pas- sat segle es va produir un canvi fonamental en la forma d'entendre l'autoconcepte, de tal forma que passa d'una visió unidimensional, defensada per autors com Coopersmith (1967), a una altra multidimensional, emparada per autors com Burns (1990), Rosenberg (1979), Shavelson, Hubner i Stanton (1976) o l'Ecuyer (1985). No obstant això, anys enrere, altres investigadores, com 
Staines (1954) o Allport (1955), ja consideraven aquesta naturalesa. Un dels models que ha tingut més repercussió dins aquesta nova perspectiva és el concebut per Shavelson et al. (1976).

L'autoconcepte pot evolucionar de manera gradual i ordenada, passant d'un estat més global a una major diferenciació i integració jeràrquica (Saura, 1996). A mesura que la persona es desenvolupa, les dimensions de l'autoconcepte canvien, s'assenten o en poden aparèixer de noves, encara que es rebutja que sigui quelcom absolutament canviant, atès que la persona necessita un sentit d'identitat més o menys estable en la seva vida (González \& Tourón, 1992). L'Ecuyer (1985) proposa una sèrie de fases en l'evolució de l'autoconcepte, denominant la que engloba la mostra del nostre estudi diferenciació del self (10-12 anys a 18-20 anys). En aquesta succeeix un procés de revisió, diferenciació i reformulació de si mateix (Esnaola, 2005), ja que apareixen percepcions més profundes i succeeixen grans canvis socials, físics o cognitius, augmenta l'autonomia, apareixen noves ideologies, etc.

L'autoconcepte condiciona, en certa manera, les conductes de les persones. Per a l'adolescent, conèixer-lo pot ajudar a prevenir el consum de drogues o alcohol, associar-se a grups violents, caure en la depressió, etc., ja que tot això sol aparèixer quan hi ha un autoconcepte negatiu de si mateix que aparta de la veritable recerca de la pròpia identitat (Esnaola, 2005). Per tant, un bon autoconcepte ajuda en l'adolescència a dur a terme conductes saludables (Pastor, Balaguer, \& García, 2000) i a tenir una major satisfacció amb la vida (Balaguer, 2001).

Una de les seves dimensions, l'autoconcepte físic, ha estat definit com la representació mental multidimensional que les persones tenen de la seva realitat corporal, inclosos elements perceptius, cognitius, afectius, emocionals $\mathrm{i}$ altres aspectes relacionats amb el que és corporal (Marchago, 2002). És una dimensió de l'autoconcepte que, des dels anys noranta del segle passat, ha estat fortament estudiada (Esnaola, Goñi, \& Madariaga, 2008). Segons Musitu, Buelga, Lila i Cava (2001), en nens i adolescents es va desenvolupant a través de la interacció directa, els processos autoperceptius i la comparació social, de manera que existeix una evolució en el temps, i és més complex i transcendent a mesura que ens anem endinsant en les últimes fases de l'adolescència.

Són diverses les investigacions que han indagat en les relacions entre l'autoconcepte físic i la pràctica fí- sicoesportiva. Estudis com els fets per Goñi i Zulaica (2000), Alvariñas i González (2004) o Moreno i Cervelló (2005) van demostrar una millor percepció d'aquest quan es feia pràctica física, i n'és determinant la freqüència de pràctica. En la tesi doctoral feta per Hellín (2007) les dades obtingudes indiquen, a més a més, que els nois tenen millors puntuacions que les noies. Candel, Olmedilla i Blas, (2008) en un estudi fet sobre 226 noies adolescents de la regió de Múrcia, en edats compreses entre els 16 i els 19 anys, obtenen resultats que indiquen que el grup que feia algun tipus d'activitat física tenia puntuacions superiors en els factors de l'autoconcepte que es van analitzar en l'estudi: acadèmic, social, familiar i físic, però no en l'emocional.

Aquesta investigació tracta de relacionar la freqüència d'activitat físic esportiva en temps d'oci, estudiada sobre una mostra d'adolescents en edat escolar, amb els seus nivells d'autoconcepte físic multidimensional. La hipòtesi que dóna origen a aquest text indica l'augment produit en els nivells del constructe objecte d'estudi d'acord amb la pràctica física i la seva freqüència.

\section{Mètode}

\section{Mostra}

Els participants d'aquest estudi van ser 2.079 adolescents de Màlaga capital, el $46,6 \%$ nois $(n=969)$ i el $53,4 \%$ noies $(n=1.110)$. Pertanyien als nivells educatius $3 \mathrm{r}$ i $4 \mathrm{t}$ de secundària $\mathrm{i} 1 \mathrm{r}$ de batxillerat, en edats compreses entre els 14 i 17 anys $(M=15,62$; $D T=0,95)$. La selecció de la mostra va ser mitjançant procés aleatori per conglomerats, polietàpic estratificat (Ramos, Catena, \& Trujillo, 2004).

\section{Instruments}

La presa de dades es va dur a terme mitjançant diversos qüestionaris, gràcies als quals es va obtenir informació sobre el sexe, si feien activitat fisicoesportiva en temps d'oci i la freqüència setmanal de pràctica. En segon lloc, mesurem el seu autoconcepte físic gràcies al Qüestionari d'Autoconcepte Físic (CAF) elaborat per Goñi, Ruiz de Azúa i Rodríguez (2004), en el qual es poden establir les dimensions següents: habilitat física $(\mathrm{H})$, condició física $(\mathrm{C})$, atractiu físic $(\mathrm{A})$, força $(\mathrm{F})$. A més a més, mesura l'autoconcepte físic general (AFG) i l'autoconcepte general (AG). Aquest instrument està format per 36 ítems, 20 d'aquests redactats de manera 
directa i 16 de manera inversa. Es va contestar mitjançant una escala de l'1 al 4: 1 és un grau de desacord alt amb el que dicta l'ítem i 4, un grau d'acord alt.

Les anàlisis de fiabilitat (Alfa de Cronbach) originals (Goñi, Ruiz de Azúa, \& Liberal, 2004) van ser de 0,80 per a habilitat física, 0,83 per a força, 0,84 per a condició física i 0,88 per a atractiu físic; per a les subescales d'autoconcepte físic general va ser de 0,88 i per a la d'autoconcepte general, 0,79. S'ha utilitzat en diversos estudis en què s'ha demostrat la capacitat d'aquest instrument per mesurar aquest constructe. Goñi, Ruiz de Azúa i Rodríguez (2004), per exemple, van aplicar el qüestionari a diversos grups de població, un d'adolescents i un altre d'universitaris, i es va poder observar com en dimensions com l'habilitat física, condició física i força les puntuacions decreixien amb l'edat. En un altre estudi fet per Goñi, Ruiz de Azúa i Liberal (2004) sobre 343 estudiants d'entre 13 i 16 anys de les províncies de Burgos i Guipúscoa, les dades van indicar l'existència de diferències entre nois i noies a favor dels nois, encara que en la mesura autoconcepte general la diferència és menys significativa.

\section{Procediment}

Per desenvolupar aquesta investigació, hem seguit un tipus de metodologia no experimental (Ramos et al., 2004) identificada com de tipus transversal o també anomenada correlacional (Salkind, 1999), en el qual s'usa l'enquesta com a eina per a la presa de dades sense produir-se en cap moment manipulació de les variables objecte d'estudi. Les tècniques estadístiques utilitzades van ser T-student i ANOVA d'un factor, la qual cosa ens ha permès observar si la variació en el valor obtingut per a la variable autoconcepte, en les seves múltiples dimensions, ha tingut una variació significativa en funció de la condició d'individus actius i la seva freqüència de pràctica setmanal. El processament de les dades es va fer mitjançant paquet informàtic SPSS versió 15.0.

Per a la recollida de dades, vam ser als centres escolars seleccionats, on vam demanar permís prèviament. Els qüestionaris van ser autoadministrats, encara que es van explicar adequadament $\mathrm{i}$ es va estar present mentre eren complimentats per resoldre possibles dubtes. Es van reomplir a l'aula, i la durada mitjana era de 15 minuts. Les dades recollides van fer possible distribuir la mostra en grups que indicaven l'existència o no de pràctica física i la seva freqüència setmanal d'activitat (taula 1). Després d'aquesta organització, vam poder avaluar les puntuacions obtingudes en les diferents subescales del CAF.

\section{Resultats}

\section{Fiabilitat de l'instrument}

Les anàlisis de fiabilitat fetes per al nostre estudi mostren uns nivells adequats, de tal forma que s'ha obtingut una consistència interna alta, mesurada a través d'Alfa de Cronbach, per a la mostra general $(\mathrm{H}$, $\alpha=0,76 ; \mathrm{C}, \alpha=0,82 ; \mathrm{A}, \alpha=0,79 ; \mathrm{F}, \alpha=0,77$; AFG, $\alpha=0,80 ; \mathrm{AG}, \alpha=0,72)$ i per als subgrups que practicaven 1 dia o menys a la setmana $(\mathrm{H}, \alpha=0,73$; $\mathrm{C}$, $\alpha=0,80 ; \mathrm{A}, \alpha=0,79 ; \mathrm{F}, \alpha=0,76$; AFG, $\alpha=0,80$; AG, $\alpha=0,72)$, els que ho feien 2 o $3(\mathrm{H}, \alpha=0,75$; , $\alpha=0,80 ; \mathrm{A}, \alpha=0,77 ; \mathrm{F}, \alpha=0,74$; AFG, $\alpha=0,77$; AG, $\alpha=0,71)$ i els que practicaven 4 dies o més $(\mathrm{H}$, $\alpha=0,76$; C, $\alpha=0,79 ; \mathrm{A}, \alpha=0,78 ; \mathrm{F}, \alpha=0,74$; AFG, $\alpha=0,77$; AG, $\alpha=0,71)$.

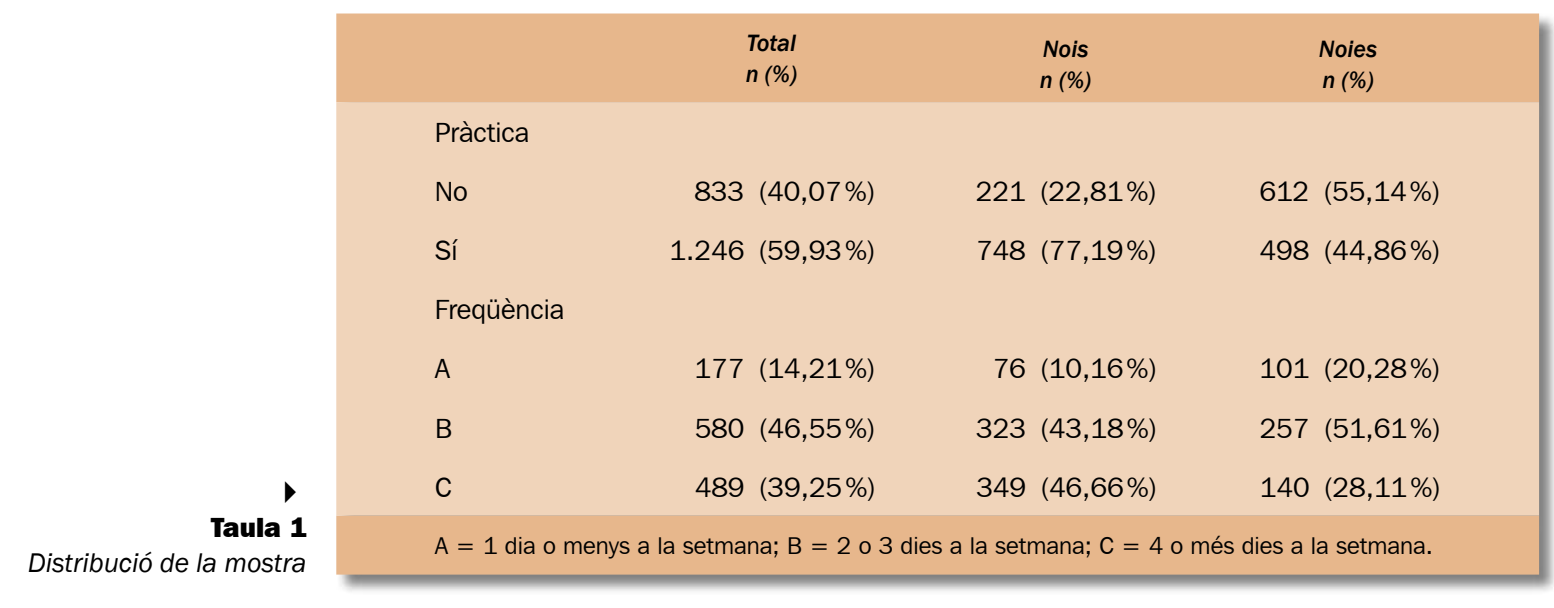




\begin{tabular}{|c|c|c|c|c|c|c|c|}
\hline & $\begin{array}{l}\text { Pràctica } \\
\text { t-student }\end{array}$ & $\begin{array}{c}\text { Habilitat física } \\
M \\
(D T)\end{array}$ & $\begin{array}{c}\text { Condició física } \\
M \\
(D T)\end{array}$ & $\begin{array}{c}\text { Atractiu físic } \\
\text { M } \\
\text { (DT) }\end{array}$ & $\begin{array}{c}\text { Força } \\
\text { M } \\
(D T)\end{array}$ & $\begin{array}{c}\text { AC físic general } \\
M \\
(D T)\end{array}$ & $\begin{array}{c}\text { AC general } \\
M \\
(D T)\end{array}$ \\
\hline \multirow[t]{3}{*}{ Total } & No & $\begin{array}{c}15,59 \\
(3,36)\end{array}$ & $\begin{array}{l}14,34 \\
(3,50)\end{array}$ & $\begin{array}{l}16,00 \\
(3,62)\end{array}$ & $\begin{array}{l}13,90 \\
(3,07)\end{array}$ & $\begin{array}{l}16,75 \\
(3,63)\end{array}$ & $\begin{array}{l}18,48 \\
(3,11)\end{array}$ \\
\hline & Sí & $\begin{array}{l}17,97 \\
(3,25)\end{array}$ & $\begin{array}{l}17,41 \\
(3,56)\end{array}$ & $\begin{array}{l}16,95 \\
(3,60)\end{array}$ & $\begin{array}{l}16,20 \\
(3,44)\end{array}$ & $\begin{array}{l}18,16 \\
(3,59)\end{array}$ & $\begin{array}{l}19,33 \\
(3,14)\end{array}$ \\
\hline & $t$ & $-16,17^{* * *}$ & $-19,42^{* * *}$ & $-5,91 * * *$ & $-15,93^{* * *}$ & $-8,71^{* * *}$ & $-6,01 * * *$ \\
\hline \multirow[t]{3}{*}{ Nois } & No & $\begin{array}{l}16,41 \\
(3,49)\end{array}$ & $\begin{array}{l}15,58 \\
(3,50)\end{array}$ & $\begin{array}{l}16,03 \\
(3,49)\end{array}$ & $\begin{array}{l}15,35 \\
(3,19)\end{array}$ & $\begin{array}{l}17,03 \\
(3,51)\end{array}$ & $\begin{array}{l}18,13 \\
(3,05)\end{array}$ \\
\hline & Sí & $\begin{array}{l}18,55 \\
(3,02)\end{array}$ & $\begin{array}{l}18,33 \\
(3,29)\end{array}$ & $\begin{array}{l}17,46 \\
(3,27)\end{array}$ & $\begin{array}{l}17,26 \\
(3,15)\end{array}$ & $\begin{array}{l}18,80 \\
(3,21)\end{array}$ & $\begin{array}{l}19,45 \\
(3,19)\end{array}$ \\
\hline & $t$ & $-8,28 * * *$ & $-10,73 * * *$ & $-5,61 * * *$ & $-7,89 * * *$ & $-7,07^{* * *}$ & $-5,46^{* * *}$ \\
\hline \multirow[t]{3}{*}{ Noies } & No & $\begin{array}{l}15,29 \\
(3,26)\end{array}$ & $\begin{array}{l}13,89 \\
(3,39)\end{array}$ & $\begin{array}{l}15,99 \\
(3,67)\end{array}$ & $\begin{array}{l}13,38 \\
(2,85)\end{array}$ & $\begin{array}{l}16,66 \\
(3,67)\end{array}$ & $\begin{array}{l}18,61 \\
(3,13)\end{array}$ \\
\hline & Sí & $\begin{array}{l}17,10 \\
(3,40)\end{array}$ & $\begin{array}{l}16,04 \\
(3,51)\end{array}$ & $\begin{array}{l}16,20 \\
(3,93)\end{array}$ & $\begin{array}{l}14,60 \\
(3,24)\end{array}$ & $\begin{array}{l}17,19 \\
(3,91)\end{array}$ & $\begin{array}{l}19,14 \\
(3,05)\end{array}$ \\
\hline & $t$ & $-9,01 * * *$ & $-10,33 * * *$ &,- 90 & $-6,63 * * *$ & $-2,37^{\star}$ & $-2,83 * * *$ \\
\hline
\end{tabular}

$\Delta$

Taula 2

Nivell d'autoconcepte segons la pràctica física, per a la mostra total i per sexe

\section{Comparacions entre grups i intra grups}

Les dades trobades en aquest treball indiquen que, en la mostra total, els participants actius van obtenir millors resultats en totes les subescales del CAF que els que no ho eren, i les majors diferències eren en habilitat física (t $2077=-16,17 ; p<0,001$ ), condició física (t $2077=-19,42 ; p<0,001)$ i força (t $2077=-15,58$; $p<0,001)$. En nois, les diferències entre participants actius i no actius van ser significatives, i les majors distàncies es trobaven en la subescala condició física (t $967=-10,73 ; p<0,001)$. Les noies actives van obtenir sempre diferències a favor seu, i les més importants eren en condició física (t $1108=-9,01 ; p<0,001$ ). No obstant això, en tots els casos no van ser significatives, com en atractiu físic (t 1031,08 $=-, 90 ; p>0,05$ ) (taula 2).

En analitzar els resultats obtinguts en les subescales del CAF d'acord amb la freqüència setmanal de pràctica física, vam poder veure que, per a la mostra general $i$ en tots els casos, com més gran era la freqüència de pràctica augmentava la percepció d'autoconcepte físic. No obstant això, encara que en gairebé tots els casos la variació va ser significativa, en autoconcepte general no va ser així $(\mathrm{F}[2,1243]=1,10, p>0,05)$. Pel que fa a nois, va ocórrer igual, atès que en tots els casos va haver-hi un augment a mesura que creixia la fre- qüència de pràctica, excepte en el cas d'autoconcepte general, en què les diferències no van ser significatives $(\mathrm{F}[2,745]=1,62, p>0,05)$. Pel que fa a noies, l'augment de l'autoconcepte va succeir només en $h a$ bilitat física $(\mathrm{F}[2,495]=11,41, \quad p<0,001)$, condició física $(\mathrm{F}[2,495]=14,15, p<0,001)$ i força $(\mathrm{F}[2,495]=12,35, p<0,001)$, perquè en els altres casos no es va generar aquest patró (taula 3 ).

La prova de Levene (taula 4) ens va indicar que podíem acceptar en tots els casos, en aplicar ANOVA d'un factor per a la mostra total i per sexe, que les variàncies entre grups eren homogènies, atès que en cap cas va haver-hi significació $(p>0,05)$. Gràcies a això, vam poder emprar la tècnica de Scheffé per comparar els subgrups.

L'estudi fet per conèixer en profunditat les diferències entre grups ens va donar l'oportunitat d'observar que, per a la mostra general, les diferències entre grups en les subescales habilitat física i condició física van ser sempre significatives $(p<0,001)$. En la subescala atractiu físic no hi havia diferències significatives entre practicar 1 vegada o menys a la setmana i fer-ho $2 / 3$, encara que sí en el cas de fer-ho 4 dies o més respecte als grups restants $(p<0,05)$, tal com succeïa també amb la subescala autoconcepte físic general $(p<0,01$; $p<0,001)$ (taula 5). 


\begin{tabular}{|c|c|c|c|c|c|c|c|}
\hline & & Habilitat física & Condició física & Atractiu físic & Força & AC físic general & $A C$ general \\
\hline & $\begin{array}{c}F / S \\
\text { t-student }\end{array}$ & $\begin{array}{c}M \\
\text { (DT) }\end{array}$ & $\begin{array}{c}M \\
(D T)\end{array}$ & $\begin{array}{c}M \\
\text { (DT) }\end{array}$ & $\begin{array}{c}M \\
(D T)\end{array}$ & $\begin{array}{c}M \\
(D T)\end{array}$ & $\begin{array}{c}M \\
\text { (DT) }\end{array}$ \\
\hline \multirow[t]{4}{*}{ Total } & 1 dia o menys & $\begin{array}{l}16,66 \\
(3,55)\end{array}$ & $\begin{array}{l}15,66 \\
(3,53)\end{array}$ & $\begin{array}{l}16,47 \\
(3,69)\end{array}$ & $\begin{array}{l}14,87 \\
(3,34)\end{array}$ & $\begin{array}{l}17,53 \\
(3,61)\end{array}$ & $\begin{array}{l}19,10 \\
(3,12)\end{array}$ \\
\hline & 203 dies & $\begin{array}{l}17,72 \\
(3,16)\end{array}$ & $\begin{array}{l}17,01 \\
(3,42)\end{array}$ & $\begin{array}{l}16,75 \\
(3,60)\end{array}$ & $\begin{array}{l}15,78 \\
(3,38)\end{array}$ & $\begin{array}{l}17,85 \\
(3,56)\end{array}$ & $\begin{array}{l}19,27 \\
(3,09)\end{array}$ \\
\hline & 4 dies o més & $\begin{array}{l}18,75 \\
(3,05)\end{array}$ & $\begin{array}{l}18,52 \\
(3,38)\end{array}$ & $\begin{array}{l}17,37 \\
(3,53)\end{array}$ & $\begin{array}{l}17,18 \\
(3,29)\end{array}$ & $\begin{array}{l}18,76 \\
(3,54)\end{array}$ & $\begin{array}{l}19,47 \\
(3,20)\end{array}$ \\
\hline & $F$ & $31,93 * * *$ & $52,95^{* * *}$ & $5,86^{* *}$ & $39,70 * * *$ & $11,89 * * *$ & 1,10 \\
\hline \multirow[t]{4}{*}{ Nois } & 1 dia o menys & $\begin{array}{l}17,42 \\
(3,30)\end{array}$ & $\begin{array}{l}16,53 \\
(3,63)\end{array}$ & $\begin{array}{l}16,46 \\
(3,64)\end{array}$ & $\begin{array}{l}16,36 \\
(3,14)\end{array}$ & $\begin{array}{l}17,66 \\
(3,34)\end{array}$ & $\begin{array}{l}18,86 \\
(3,15)\end{array}$ \\
\hline & 2 o 3 dies & $\begin{array}{l}18,33 \\
(2,96)\end{array}$ & $\begin{array}{l}17,99 \\
(3,15)\end{array}$ & $\begin{array}{l}17,20 \\
(3,24)\end{array}$ & $\begin{array}{l}16,91 \\
(3,16)\end{array}$ & $\begin{array}{l}18,44 \\
(3,20)\end{array}$ & $\begin{array}{l}19,45 \\
(3,13)\end{array}$ \\
\hline & 4 dies o més & $\begin{array}{l}19,01 \\
(2,93)\end{array}$ & $\begin{array}{l}19,03 \\
(3,15)\end{array}$ & $\begin{array}{l}17,91 \\
(3,15)\end{array}$ & $\begin{array}{l}17,78 \\
(3,05)\end{array}$ & $\begin{array}{l}19,39 \\
(3,07)\end{array}$ & $\begin{array}{l}19,58 \\
(3,26)\end{array}$ \\
\hline & $F$ & $10,60 * * *$ & $22,20 * * *$ & $7,90 * * *$ & $10,23^{* * *}$ & $13,21 * * *$ & 1,62 \\
\hline \multirow[t]{4}{*}{ Noies } & 1 dia o menys & $\begin{array}{l}16,08 \\
(3,63)\end{array}$ & $\begin{array}{l}15,00 \\
(3,31)\end{array}$ & $\begin{array}{l}16,48 \\
(3,75)\end{array}$ & $\begin{array}{l}13,75 \\
(3,04)\end{array}$ & $\begin{array}{l}17,43 \\
(3,82)\end{array}$ & $\begin{array}{l}19,29 \\
(3,09)\end{array}$ \\
\hline & 2 o 3 dies & $\begin{array}{l}16,95 \\
(3,24)\end{array}$ & $\begin{array}{l}15,78 \\
(3,36)\end{array}$ & $\begin{array}{l}16,18 \\
(3,94)\end{array}$ & $\begin{array}{l}14,36 \\
(3,10)\end{array}$ & $\begin{array}{l}17,11 \\
(3,84)\end{array}$ & $\begin{array}{l}19,05 \\
(3,04)\end{array}$ \\
\hline & 4 dies o més & $\begin{array}{l}18,11 \\
(3,26)\end{array}$ & $\begin{array}{l}17,25 \\
(3,60)\end{array}$ & $\begin{array}{l}16,04 \\
(4,05)\end{array}$ & $\begin{array}{l}15,67 \\
(3,39)\end{array}$ & $\begin{array}{l}17,18 \\
(4,12)\end{array}$ & $\begin{array}{l}19,21 \\
(3,04)\end{array}$ \\
\hline & $F$ & $11,41 * * *$ & $14,15^{* * *}$ & ,37 & $12,35^{* * *}$ &, 23 &, 27 \\
\hline
\end{tabular}

\section{Taula 3}

Nivell d'autoconcepte segons la freqüència de pràctica física, en mostra total i per sexe

\begin{tabular}{|c|c|c|c|c|c|c|c|}
\hline & & Habilitat física & Condició física & Atractiu físic & Força & $A C$ físic general & $A C$ general \\
\hline & Total & ,65 & 19 & ,65 & ,41 & ,33 & ,47 \\
\hline Taula 4 & Nois &, 59 & ,45 & 1,52 & ,08 & ,04 & ,71 \\
\hline Prova & Noies & ,32 & 1,44 & ,86 & 1,81 & ,47 & ,41 \\
\hline $\begin{array}{l}\text { Itat de } \\
\text { evene) }\end{array}$ & NOTA: & as no va ser signi & & & & & \\
\hline
\end{tabular}

d'homogeneïtat de
variàncies (Levene)

\begin{tabular}{|c|c|c|c|c|c|c|c|}
\hline & \multirow{2}{*}{$\begin{array}{l}\text { Grups segons dies } \\
\text { de pràctica setmanal }\end{array}$} & \multirow{2}{*}{$\frac{\text { Habilitat física }}{\text { Dif./Sig. }}$} & \multirow{2}{*}{$\frac{\text { Condició física }}{\text { Dif./Sig. }}$} & \multirow{2}{*}{$\begin{array}{c}\text { Atractiu fisic } \\
\text { Dif./Sig. }\end{array}$} & \multirow{2}{*}{$\begin{array}{c}\text { Força } \\
\text { Dif./Sig. }\end{array}$} & \multirow{2}{*}{$\frac{\text { AC físic general }}{\text { Dif./Sig. }}$} & \multirow{2}{*}{$\frac{A C \text { genera }}{\text { Dif./Sig. }}$} \\
\hline & & & & & & & \\
\hline \multirow[t]{3}{*}{ Total } & (1 o menys)-(2/3) & $-1,06^{* *}$ & $1,36 * * *$ &,- 28 &,$- 91^{*}$ &,- 32 &,- 17 \\
\hline & (1 o menys)-(4 o més) & $-2,10 * * *$ & $-2,87 * * *$ &,$- 90 *$ & $-2,31 * * *$ & $-1,23^{* * *}$ &,- 37 \\
\hline & (2/3)-(4 o més) & $-1,04 * * *$ & $-1,51 * * *$ &,$- 62 *$ & $-1,40 * * *$ &,$- 91 * * *$ &,- 21 \\
\hline \multirow[t]{3}{*}{ Nois } & (1 o menys)-(2/3) &,- 90 & $-1,47 * *$ &,- 74 &,- 55 &,- 78 &,- 59 \\
\hline & (1 o menys)-(4 o més) & $-1,59 * * *$ & $-2,51 * * *$ & $-1,44 * *$ & $-1,43^{* *}$ & $-1,73 * * *$ &,- 73 \\
\hline & (2/3)-(4 o més) &,$- 69 *$ & $-1,04 * * *$ &,$- 70 *$ &,$- 88 * *$ &,$- 95^{* *}$ &,- 14 \\
\hline \multirow[t]{3}{*}{ Noies } & (1 o menys)-(2/3) &,- 87 &,- 78 & ,30 &,- 61 & ,31 & ,24 \\
\hline & (1 o menys)-(4 o més) & $-2,03 * * *$ & $-2,25^{\star * *}$ & ,44 & $-1,92 * * *$ & ,25 & ,08 \\
\hline & (2/3)-(4 o més) & $-1,16 * *$ & $-1,47 * * *$ & ,14 & $-1,31 * * *$ &,- 07 &,- 16 \\
\hline
\end{tabular}

\section{Taula 5}

Comparacions múltiples segons freqüència de pràctica física setmanal 


\section{Discussió i conclusions}

Aquest treball utilitza un instrument que contribueix a l'estudi de l'autoconcepte físic multidimensional, constructe molt apropiat per explicar comportaments relatius a la pràctica física (Zulaica, 1999). Ens hem basat en arguments com els de Tomás (1998), que consideren la pràctica física continuada, gràcies a la millora de les competències físiques i altres aspectes com l'aparença física, com una eina per millorar la percepció de l'autoconcepte físic, així com de l'autoconcepte general. Els resultats trobats en el nostre estudi avalen aquesta postura i contribueixen a reforçar els efectes de l'activitat física esportiva sobre la salut psicològica de les persones. Autors com Goñi i Zulaica (2000) anunciaven que la millora en la percepció d'autoconcepte físic podria tenir implicacions en la percepció general del concepte personal.

$\mathrm{Hi}$ ha evidències en altres estudis que coincideixen amb els resultats trobats en la nostra investigació. Pastor i Balaguer (2001) van trobar resultats positius en la correlació entre pràctica física i competència percebuda, tant en nois com en noies, encara que en nois ocorria en l'adolescència primera i mitjana, $i$ en noies només en l'adolescència mitjana. D'altra banda, un estudi sobre adolescents espanyols va indicar que els qui feien pràctica física extraescolar tenien millors puntuacions en l'autoconcepte físic que els que no la duien a terme (Hellín, 2007). Candel et al. (2008), en analitzar les respostes de 226 adolescents de la regió de Múrcia en edats compreses entre els 16 i els 19 anys, van posar de manifest que el grup que feia algun tipus d'activitat física tenia puntuacions superiors en els següents factors de l'autoconcepte: acadèmic, social, familiar i físic.

D'altra banda, la literatura consultada ofereix estudis, com el fet per Moreno, Atienza i Balaguer (1997), que assenyalen com l'autoconcepte físic millora quan una persona fa exercici físic amb regularitat. A més a més, Moreno, Moreno i Cervelló (2007) van demostrar, a través d'un estudi, que els adolescents que practicaven activitat física, i sobretot si es duia a terme ben sovint, experimentaven una millora de les percepcions en competència percebuda, atractiu corporal, condició física i força, i els nois eren els que presentaven millors puntuacions. Alvariñas i González (2004) van fer un estudi sobre estudiants entre 14 i 17 anys de la província de la Corunya i van comprovar com aquelles persones que feien més quantitat d'exercici físic tenien una millor percepció de les seves competències físiques que les que eren sedentàries, igual que una major satisfacció amb el seu aspecte físic.
En el nostre treball, hem trobat dades que coincideixen amb les comentades anteriorment, atès que revelen una major percepció de l'autoconcepte físic quan es fa més activitat físic esportiva setmanal. Per a la mostra total, i pel que fa a nois, es produeix un augment en cada factor del qüestionari utilitzat que demostra les similituds amb aquests estudis. No obstant això, en el cas de les noies no ocorre en les subescales atractiu físic i autoconcepte físic general. No queda clar si es pot generalitzar com una diferència estable entre nois i noies, encara que sí que pot ser un punt de partida per a investigacions posteriors.

Els nostres resultats deixen en l'aire conclusions extretes en altres treballs, com el dut a terme per Goñi i Zulaica (2000) entre escolars, el qual va indicar que aquells que eren actius tenien millor percepció de l'autoconcepte; i no sols això, sinó que els que participaven amb més freqüència tenien millors resultats que els altres. A més a més, anys enrere, McDonald i Hodgdon (1991) i altres autors van assenyalar que la pràctica d'exercici millorava l'autoconcepte global, però era necessari dur-lo a terme com a mínim tres vegades a la setmana, amb una durada important i, perquè es veiessin els resultats, mantenir-lo al llarg del temps (Leith, 1994; Frederick \& Ryan, 1993). És cert que, per a la mostra total i en nois, la tendència coincideix amb allò que s'ha postulat en aquests treballs, encara que cal assenyalar la falta de significació. No obstant això, en noies no es reprodueix aquest patró de comportament i no s'aprecia una millora de l'autoconcepte general a mesura que es practica amb major freqüència setmanal.

A la llum dels nostres resultats, hem de dir que la pràctica física condueix a millorar la percepció de l'autoconcepte físic i general, encara que no queda clar que tingui conseqüències generalitzades per a tota la població quan tenim en compte la freqüència amb què es practica. Podem concloure el nostre treball exposant una sèrie d'idees que creiem importants: d'una banda, Marsh (1986) considerava que si volem realitzar un programa d'activitat amb la finalitat d'incidir sobre certs aspectes, hem de tenir en compte la durada, intensitat, planificació, objectius i continguts; d'una altra, Marchago (1991) creu a més a més que s'ha d'adaptar a les circumstàncies específiques de cada cas i que els exercicis s'han de succeir en l'ordre programat, de tal forma que es respecti l'ordre en què estaven previstos per no incórrer en errors que impedeixin assolir els objectius previstos. 


\section{Referències}

Aguilar, M. C. (2003). Perspectiva biológica, cognitiva y experiencial del concepto de sí mismo. Revista de Psicología General y Aplicada, 56(2), 185-199.

Allport, G. W. (1955). Becoming: Basic Considerations for a Psychology of Personality. New Haven: Yale University Press.

Alvariñas, M. \& González, M. (2004). Relación entre la práctica físico-deportiva extraescolar y el autoconcepto físico en la adolescencia. Revista de Educación Física (94), 5-8.

Balaguer, I. (agost, 2001). Achievement Goals and Health Behaviours: Investigating PoSsible Social Psychological Mechanisms. Presentat a la XIX Convención Anual de la Asociación de Psicología Americana. San Francisco.

Burns, R. B. (1990). El autoconcepto. Teoría, medición, desarrollo y comportamiento. Bilbao: EGA.

Candel, N., Olmedilla, A., \& Blas, A. (2008). Relaciones entre la práctica de actividad física y el autoconcepto, la ansiedad y la depresión en chicas adolescentes. Cuadernos de Psicología del Deporte, $8(1), 61-77$

Coopersmith, S. (1967). The Antecedents of Self-esteem. W. H. Freeman: San Francisco.

Esnaola, I. (2005). Desarrollo del autoconcepto durante la adolescencia y principio de la juventud. Revista de Psicología General y Aplicada, 58(2), 265-277.

Esnaola, I., Goñi, A., \& Madariaga, J. M. (2008). El autoconcepto: perspectivas de investigación. Revista de Psicodidáctica, 13(1), 179194.

Frederick, C. M. \& Ryan, R. M. (1993). Differences in motivation for sport and exercise, and their relationships with participation and mental health. Journal of Sport Behaviour, 16, 124-126.

González, M. C. \& Tourón, J. (1992). Autoconcepto y Rendimiento Escolar. Pamplona: EUNSA.

Goñi, A., Ruiz de Azúa, S., \& Liberal, I. (2004). Propiedades psicométricas de un nuevo cuestionario para la medida del autoconcepto físico. Revista de Psicología del Deporte, 13(2), 195-213.

Goñi, A., Ruiz de Azúa, S., \& Rodríguez, A. (2004). Esport i autoconcepte físic en la preadolescència. Apunts. Educació Física i Esports (77), 18-24

Goñi, A. \& Zulaika, L. M. (2000). La participació en l'esport escolar i l'autoconcepte en escolars de 10 a 11 anys de la província de Guipúscoa. Apunts. Educació Física i Esports (59), 6-10.

Hellín, M. ${ }^{a}$ G. (2007). Motivación, autoconcepto fisico, disciplina y orientación disposicional en estudiantes de Educación Física (Tesi doctoral). Universidad de Murcia, Murcia.

L'Ecuyer, R. (1985). El concepto de sí mismo. Madrid: Oikos-Tau.

Leith, L. M. (1994). Foundations of Exercise on Mental Health. Morgatown, WV: Fitness Information Technology.

Marchago, J. (1991). El profesor y el autoconcepto de sus alumnos: teoría y práctica. Barcelona: CISS-Praxis (Escuela Española).

Marchago, J. (2002). Autoconcepto físico y dilemas corporales de la ciudadanía adolescente. Revista Psicosocial (2), 1-25.
Marsh, H. W. (1986). The Self Description Questionnaire (SDQ): A Theoretical and Empirical Basis for the Measurement of Multiple Dimensions of Preadolescent Self-Concept: A Test Manual and a Research Monograph. NSW Austràlia: Faculty of Education, University of Sydney.

McDonald, D. G. \& Hodgdon, J. A. (1991). Psychological Effects of Aerobic Fitness Training. New York: Springer-Verlag.

Moreno, J. A. \& Cervelló, E. (2005). Physical self-perception in Spanish adolescents: effects of gender and involvent in physical activity. Journal of Human Movement Studies, 48, 291-311.

Moreno, J. A., Moreno, R., \& Cervelló, E. (2007). El autoconcepto físico como predictor de la intención de ser físicamente activo. Revista de Psicología y Salud, 17(2), 261-267.

Moreno, Y., Atienza, F. L., \& Balaguer, I. (1997). La actividad fisica como predictora de la autoestima global y la autopercepción fisica. VI Congreso Nacional de Psicología Social. San Sebastián.

Musitu, G., Buelga, S., Lila, M. S., \& Cava, M. J. (2001). Familia y adolescencia: un modelo de análisis e intervención psicosocial. Madrid: Síntesis.

Pastor, Y. (1999). Un estudio de la influencia del autoconcepto multidimensional sobre el estilo de vida saludable en la adolescencia media (Tesi doctoral). Universitat de València, València.

Pastor, Y. \& Balaguer, I. (2001). Relaciones entre autoconcepto, deporte y competición deportiva en los adolescentes valencianos. Congreso Internacional Online de Psicología Aplicada. Recuperat de http://www.psicología-online/cipoa2001/actividades/57/

Pastor, Y., Balaguer, I., \& García, M. L. (2000). Influence of multidimensional self-concept on health related lifestyle. International Journal of Psychology, 35(3/4), 169.

Ramos, M. M., Catena, A., \& Trujillo, H. M. (2004). Manual de métodos y técnicas de investigación en ciencias del comportamiento. Madrid: Biblioteca Nueva.

Rosenberg, M. (1979). Conceiving the Self. New York: Basic Books.

Salkind, N. J. (1999). Métodos de investigación. México: Prentice Hall.

Saura, P. (1996). La educación del autoconcepto: cuestiones y propuestas. Murcia: Servicio de Publicaciones Universidad de Murcia.

Shavelson, R. J., Hubner, J. J., \& Stanton, J. C. (1976). Self-concept: validation of construct interpretations. Review of Educational Research, 46(3), 407-441. doi:10.2307/1170010

Staines, J. W. (1954). A Sociological and Psychological Study of the Self-picture and its Importance in Education (Tesi doctoral). Universidad de Londres, Londres.

Tomás, I. (1998). Equivalencia psicométrica de una traducción del cuestionario de autoconcepto fisico PSDQ (Physical Self-Description Questionnaire) al castellano (Tesi doctoral). Universitat de València, València.

Zulaica, L. (1999). Educación Física y mejora del autoconcepto. Revista de Psicodidáctica (8), 101-120. 